\title{
Implementation of Evidence-Based Preventive Services Delivery Processes in Primary Care: An Oklahoma Physicians Resource/Research Network (OKPRN) Study
}

\author{
James W. Mold, MD, MPH, Cheryl A. Aspy, PhD, and Zsolt Nagykaldi, PhD
}

Background: Previous research has found that wellness visits, recall and reminder systems, and standing orders are associated with higher rates of delivery of preventive services in primary care practices. However, there is little information about how to help practices implement these processes.

Methods: A 6-month randomized, controlled trial comparing a multicomponent quality improvement intervention to feedback and benchmarking. One clinician/nurse team from each of 24 practices was randomly assigned to one of 2 study arms. Intervention practices received performance feedback, peerto-peer education (academic detailing), a practice facilitator, and computer (information technology) support. Implementation of the 3 targeted processes was determined by a blinded 3-clinician panel that reviewed transcribed clinician interviews before and after intervention using performance definitions. Rates of delivery of selected preventive services were determined by chart audit.

Results: Intervention practices implemented more of the processes than control practices overall $(P=.003)$, for adults $(P=.05)$, and for children $(P=.04)$. They were also more likely to implement at least one of the processes for children $(P=.04)$ and to implement standing orders for either children or adults $(P=.02)$. Mammography rates increased significantly. Neither clinician and practice characteristics nor clinician readiness to change predicted implementation.

Conclusions: A multicomponent implementation strategy consisting of feedback, benchmarking, academic detailing, facilitation, and IT support increased implementation of evidence-based processes for delivering preventive services to a greater extent than performance feedback and benchmarking alone. (J Am Board Fam Med 2008;21:334-344.)

The published literature suggests that the most effective ways to increase the delivery of primary

This article was externally peer reviewed.

Submitted 9 January 2008; revised 28 April 2008; accepted 29 April 2008.

From the Department of Family and Preventive Medicine, University of Oklahoma Health Sciences Center, Oklahoma City.

Funding: Supported by a grant from The Agency for Healthcare Research and Quality (5 R21 HS041850-02) for the project period of September 30, 2004, through September 29, 2006.

Conflict of interest: none declared.

Corresponding author: James W. Mold, MD, MPH, Department of Family and Preventive Medicine, University of Oklahoma Health Sciences Center, 900 NE 10th Street, Oklahoma City, OK 73104 (E-mail: james-mold@ouhsc.edu).

\footnotetext{
See Related Commentary on Page 258.
}

and secondary preventive services include implementation of nurse standing orders, ${ }^{1-3}$ decisionsupport systems, ${ }^{4-9}$ and wellness visits. ${ }^{10-12}$ Combinations of these processes are more effective than the individual ones. ${ }^{13-15}$

Helping primary care practices change their care processes is a challenge. ${ }^{16-20}$ A variety of approaches have been tried, including education, performance feedback with benchmarking, academic detailing, organizational assessment and practice re-engineering, practice facilitation, computerized decision support, and financial incentives like payfor-performance. Multicomponent interventions work better than individual ones. ${ }^{21}$

Feedback with Benchmarking.

Primary care clinicians overestimate how well they deliver preventive services. However, there is little evidence that performance feedback alone changes 
clinician behavior very much in most cases. ${ }^{22,23}$ In addition to standard performance feedback, benchmarking compares individual performance to the performance of other practices to construct performance targets, generally at the 90th percentile. In a randomized controlled trial conducted by Kiefe et $\mathrm{al}^{24}$ feedback with benchmarking resulted in greater improvements in diabetes care than feedback alone. However, in a majority of studies, these strategies alone have been relatively ineffective.

\section{Academic Detailing}

Academic detailing has been shown to be effective for changing certain clinician behaviors, including the delivery of smoking cessation counseling ${ }^{25}$ and appropriate use of antibiotics, ${ }^{26}$ although it was ineffective in increasing cervical cancer screening rates $^{27}$ and implementation of depression management guidelines. ${ }^{28}$ A Cochrane review by O'Brien et $\mathrm{al}^{29}$ concluded that "educational outreach visits, particularly when combined with social marketing, seem to be a promising approach to modifying professional behavior, especially prescribing." Our approach to academic detailing includes review and discussion of both published information and the methods used by local clinicians or practices who perform the desired function at a high level. ${ }^{30}$

\section{Practice Facilitation}

Nagykaldi et $\mathrm{al}^{31}$ recently reviewed the English language literature pertaining to the use and effectiveness of practice facilitators. Although there have been no randomized trials of practice facilitation apart from other complementary interventions, the literature suggests that this approach has value. $^{32-39}$

Rogers $^{40}$ refers to practice facilitators as "change agents." He states that, "for this [type of communication/intervention] to be effective, the innovations must be selected to meet the client's needs," and "feedback from the client system must flow through the change agent to the change agency so that it appropriately adjusts its programs to fit the changing needs of clients." Our practice facilitators were called practice enhancement assistants (PEAs).

\section{Information Technology}

The Institute of Medicine Report "Crossing the Quality Chasm" states that "information technol- ogy (IT) has enormous potential to improve the quality of health care with regard to all 6 of the aims" set forth in the report (safety, effectiveness, patient-centeredness, timeliness, efficiency, and equity). ${ }^{41}$ IT applications can be used to enhance translation by giving clinicians and office staff tools that both facilitate and require changes in their office systems. Once these changes have been made, the existence of the technology may make it more difficult for the practice to revert back to previous processes.

The Preventive Services Reminder System (PSRS), an IT application that we helped to develop, delivers real-time immunization and preventive services reminders to clinicians and can be used to send reminder notices to patients. ${ }^{42}$ PSRS prompts are based on current United States Preventive Services Task Force and Advisory Committee on Immunization Practices recommendations. Flow sheets, immunization records, and audits are generated. The PSRS did not interface directly with the electronic health records being used in the practices.

The purposes of the present study were to (1) determine the effectiveness of our multicomponent intervention on implementation of 3 processes previously shown to be associated with increased delivery of preventive services: nurse standing orders, reminder/recall systems, and wellness visits; (2) identify contextual facilitators and barriers to the implementation of the 3 processes; and (3) measure the impact of the intervention on rates of delivery of preventive services. The multicomponent intervention tested in this study included feedback with benchmarking, academic detailing, practice facilitation, and IT support.

\section{Methods \\ Study Design}

This was a randomized controlled trial examining the combination of audit with feedback and benchmarking, academic detailing, practice facilitation, and IT support compared with feedback and benchmarking alone on implementation of wellness visits, recall and reminder systems, and standing orders in primary care practices (Figure 1). The primary outcomes were the number of practices who implemented one or more of these evidence-based processes and the total number of processes implemented, as determined by a 


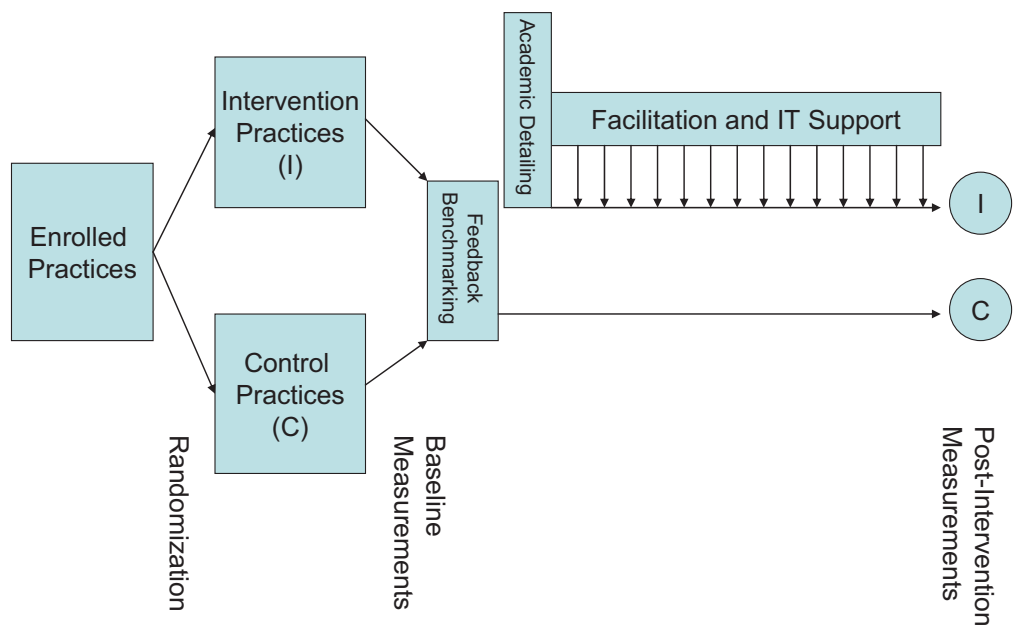

Figure 1. Randomized trial comparing feedback and benchmarking to a multicomponent implementation intervention that also included academic detailing, practice facilitation, and IT support.

blinded expert panel from transcripts of structured clinician interviews conducted at baseline and after a 6-month intervention period.

\section{Recruitment, Enrollment, and Randomization}

The study population included clinician members of the Oklahoma Physicians Resource/Research Network, who were notified of the study via listserv, fax, and personal calls by the principal investigator (JWM). Of the 94 eligible practices in the network, 24 (25\%) agreed to participate in this project. Practices were eligible to participate if individual clinicians and their nurses were able to make changes in the care process and/or had the full support of other relevant members of the practice, provided care to either 2- to 3-year-olds or 50to 75 -year-olds or both, and saw more than 30 patients per week.

One clinician from each practice was recruited and enrolled as described below. Although more than one clinician from a practice could be involved, one clinician from each practice was designated as the primary clinician participant at that clinic, and all outcome data were collected from that clinician and his/her patients' records. This allowed us to avoid statistical issues relating to clinicians clustered within practices.

The purpose and experimental nature of the project was explained to the clinicians, their nurses or medical assistants, and their clinic administrators, who signed informed consent documents approved by the University of Oklahoma Institutional
Review Board and all other applicable institutional review boards. The 24 practices were then randomized, within blocks of 4 using a series of coin tosses, to intervention and control groups of 12 practices each. It was not possible to completely blind participating clinicians. They were told that we were studying their ability to implement changes in their office systems designed to improve their rates of delivery of preventive services, and that some participating practices would receive more assistance than others.

\section{Baseline Data Collection}

At baseline, participating clinicians were asked to verify information contained in the Oklahoma Physicians Resource/Research Network database about themselves and their practices. They completed paper and pencil surveys containing questions about (1) the perceived importance to them of selected immunizations and preventive services; (2) their estimation of the rates at which their patients were receiving those services; and (3) their level of confidence that they could increase their delivery of the services by $10 \%$ during the study period. Intervention clinicians were also asked to rate (1) their readiness to increase delivery of those preventive services; (2) their level of confidence in the practice's ability to institute recall and reminder systems, standing orders, and wellness visits (rated individually); and (3) important barriers to the implementation of each of these processes in their practice. All clinicians completed (self-adminis- 
tered with PEA assistance if requested) an Assessment of Chronic Illness Care (ACIC) survey instrument (version 3.5, modified by us for preventive services). ${ }^{43}$ The ACIC instrument yields scores for each of 7 subsections $(0-11)$ and a mean overall score $(0-11)$ that represents the degree to which the practice has implemented the components of the chronic care model. ${ }^{4,45}$

Clinicians in both groups were interviewed by a research assistant, blinded to group assignment, about whether and the extent to which they were using nurse standing orders; a decision-support system providing prompts, reminders, and recalls; and/or special immunization or preventive services clinics. The interviews followed a strict protocol and were audiotaped and transcribed.

The research assistant audited the medical records of a random sample (from a computergenerated randomized numbers lists) of fifty 50 - to 75 -year-olds and fifty 2 - to 3 -year-olds seen by the index clinician within the previous 4 months. One hundred adult charts were audited in practices that saw only adults. Selected preventive services were considered up-to-date based on the following criteria: DTaP\#4, measles/mumps/rubella, HepB\#3 and Pneumovax if ever received; mammography, if received within the past 2 years; and colorectal cancer screening if fecal occult blood testing was received within 1 year, flexible sigmoidoscopy if received within 5 years, or colonoscopy if received within 10 years. First visits to the practice were not excluded.

\section{Intervention}

At baseline, clinicians in both groups were given a report listing their rates of delivery of selected preventive services including $\mathrm{DTaP} 44$, measles/ mumps/rubella \#1, and HepB\#3 for 2- to 3-yearolds; and pneumonia vaccination, colorectal cancer screening, and mammography for 50- to 75-year olds. Benchmark rates $\left(90^{\text {th }}\right.$ percentiles) were determined from clinician audits done as part of another study done in the previous year that involved 50 network clinicians.

The principal investigator (JWM), a practice facilitator (PEA), and an IT professional met with individual intervention practices (clinicians, nurses or medical assistants, and clinic administrators) for 90 minutes over lunch to discuss the 3 evidencebased processes and how they were being or might be applied in their practices. Supporting materials were supplied in a notebook that was left with the practice. The PEA assigned to that practice was introduced and her role was clarified, a schedule of visits was agreed upon, and a tentative agenda or set of tasks for the PEA was discussed. The IT professional briefly demonstrated the PSRS application and offered to install it in interested practices.

The PEA was available, on average, one-half day per week to help the staff to implement the office system strategies. Types of assistance offered included organizing staff meetings; facilitating incremental, short-cycle improvements; investigating billing and reimbursement issues; developing or modifying forms; training staff; auditing charts; sharing ideas and methods from other practices; and communicating problems, needs, and requests to the IT programmer. The actual services provided to each practice were different based upon their specific needs and requests.

If the practice chose to use the PSRS, the IT professional made additional visits to load active patients' demographic information from the practice's billing system into the application and teach the nurses or medical assistants to use it.

\section{Data Collection After Intervention}

Six months after the academic detailing visits, clinicians in the intervention group completed a follow-up survey asking about the barriers they encountered when implementing each of the processes. They also completed the ACIC instrument.

The research assistant again conducted blinded, structured, audiotaped interviews with clinicians in both groups about whether and to what extent they were using each of the targeted processes in adults and children. One of the researchers (CBA) subsequently conducted audiotaped exit interviews with the PEAs, asking them the same questions.

The research assistant again audited the medical records of a random sample (from a computergenerated randomized numbers lists) of fifty 50 - to 75 -year-olds and fifty 2 - to 3 -year-olds seen by the index clinician within the previous 4 months. One hundred adult charts were audited in practices that saw only adults.

\section{Outcome Measures}

A committee of 3 academic family physicians not otherwise involved in the project analyzed 6 sample interview transcripts and then met to operational- 
ize the existing definitions for the 3 processes. These definitions were then tested on 6 additional sample transcripts and further refined. Modifications were required to differentiate practices that used the processes occasionally from those who were using them consistently. Interview questions were then created to capture the required information. Implementation of the 3 processes by study participants was determined by consensus of the same 3 physicians, blinded to group assignment and to baseline or follow-up status. Committee members scored the transcripts independently and then met to resolve differences. Each practice received up to 6 separate dichotomous scores $(0,1)$ for the 3 processes for adults and for children (maximum: 3 $+3=6$ ). Practices that saw only adults received only 3 scores. The operational definitions used for the 3 evidence-based processes follow.

\section{Standing Orders}

Use of specific, formal protocols, policies, and procedures that authorize office nurses, medical assistants, other nonclinical office staff or pharmacists affiliated with the practice to deliver immunizations and/or other preventive services without checking with the clinician first. The protocols, policies, and procedures must be in active use with more than $50 \%$ of patients and must apply to more than a single immunization or preventive service. They need not be in written form.

\section{Reminders}

Paper-based or electronic techniques for reminding clinicians, nurses, and/or other clinic staff to recommend or perform preventive services when they are due or overdue. Reminder systems may also be, but are not required to be, used to remind patients that they are due for preventive services. An auditable registry is desirable but not required. The prompt and reminder system or systems must be used more than $50 \%$ of the time and must apply to more than a single immunization or preventive service.

\section{Special Immunization/Prevention Clinics}

Specific types of visits (eg, well-child and well-adult visits) and/or time periods (eg, immunization clinics, prevention group visits) devoted primarily to provision of preventive services. These visits or time periods must be provided to more than 50\% of patients and must apply to more than a single immunization or preventive service.

\section{Process Measures}

The following process variables were measured: (1) attendance at initial meetings with practices; (2) number of visits by the PEAs to each practice and total contact time with clinicians and staff; (3) number of visits by the IT professional to each practice; and (4) number and proportion of clinicians involved in each practice. The PEAs also wrote progress notes after each visit, which were reviewed by the principal investigator for important themes.

\section{Statistical Analyses}

Analyses of the primary outcome measures included comparisons of the following variables between intervention and control groups: (1) proportion of total opportunities for implementation of the processes (ie, processes not already in place at baseline) in which the processes were implemented; (2) the proportion of practices implementing any of the 3 processes for children or adults when an opportunity existed to implement them; and (3) the proportion of practices implementing each of the 3 processes when opportunity existed to implement them. These comparisons were made using the binomial comparison of proportions.

Associations between the variables obtained from the surveys before and after intervention, clinician and practice characteristics, and the adoption of one or more of the strategies (ie, improvement $=$ yes/no) were analyzed by logistic regression modeling. Rates of change of delivery of preventive services were compared using independent $t$ tests. Changes from baseline to final ACIC scores were compared using paired $t$ tests.

\section{Power Analysis}

The study was powered to have a better than $80 \%$ chance to detect an implementation rate twice as high in the multicomponent intervention group, assuming between 36 and 48 opportunities per group.

\section{Results}

Table 1 lists the characteristics of the clinicians and practices enrolled in the study. In the intervention group, 11 of the 12 clinicians were family physicians; the other was a physician assistant. In the control group, 11 of the clinicians were family physicians and the other was a general internist. The practices ranged in size from single clinician 


\begin{tabular}{|c|c|c|c|}
\hline Baseline Characteristics & Intervention (n) & Control (n) & $P$ \\
\hline \multicolumn{4}{|l|}{ Location* } \\
\hline Rural & 9 & 3 & \\
\hline Suburban & 2 & 5 & .05 \\
\hline Urban & 1 & 4 & \\
\hline \multicolumn{4}{|l|}{$\mathrm{Size}^{\dagger}$} \\
\hline Solo & 5 & 7 & \\
\hline $2-4$ & 5 & 2 & .40 \\
\hline $5+$ & 2 & 3 & \\
\hline \multicolumn{4}{|c|}{ Participating clinician's years in practice } \\
\hline $1-10$ & 3 & 7 & \\
\hline $11-20$ & 3 & 2 & .39 \\
\hline $21-30$ & 3 & 2 & \\
\hline $31-40$ & 3 & 1 & \\
\hline \multicolumn{4}{|l|}{ Clinician's autonomy ${ }^{\ddagger}$} \\
\hline Yes & 11 & 8 & .13 \\
\hline No & 1 & 4 & \\
\hline ACIC score (mean $[\mathrm{SD}]$ ) & $4.41(1.55)$ & $5.81(1.95)$ & .06 \\
\hline \multicolumn{4}{|c|}{ Perceived importance of preventive services $\$$} \\
\hline Immunizations & $13.3(4.7)$ & $15.1(1.9)$ & .22 \\
\hline Counseling & $13.3(2.0)$ & $13.8(2.6)$ & .61 \\
\hline Screening & $14.2(2.6)$ & $13.3(4.3)$ & .57 \\
\hline
\end{tabular}

*Urban, population of $>100,000$; suburban, population of 25-100,000; rural, population of $<25,000$.

${ }^{\dagger}$ Number of full-time equivalent clinicians in the practice.

${ }^{\ddagger}$ Clinician's ability to make independent decisions regarding how to organize his/her preventive care processes.

${ }^{\S}$ On a scale of $0-16$, with higher scores indicating greater perceived importance.

ACIC, Assessment of Chronic Illness Care.

practices to a Federally qualified community health center with 6 clinicians. Two practices (one in each group) were residency training sites. Baseline ACIC scores ranged from 2.4 to 10.1 .

Clinicians assigned to the intervention group were more likely to be rural. Those assigned to the control practices were less likely to see children. In addition, one control group practice had already implemented all the proposed processes and so had no opportunity for improvement. As a result, intervention practices had a total of 38 opportunities for improvement whereas control practices had only 23. Intervention practices were more often rural. Aside from this, intervention and control practices did not differ in size or baseline ACIC score and clinicians from the 2 groups did not differ in number of years in practice, level of autonomy, or perceived importance of preventive services (Table 1).

Table 2 lists the primary outcome variables for both intervention and control practices for both adults and children. The $P$ values shown are 2-tailed, which provides a conservative estimate of the statistical significance of the results. Clearly, standing orders were easiest to implement, followed by recall and reminder systems, followed by wellness visits. None of the practices actually recalled patients for preventive services. Mean (SD) changes in the ACIC scores were 0.77 (1.72) for the intervention practices and -0.49 (1.74) for the control practices $(P=.09)$. In one of the control practices, the use of wellness visits in children fell below the threshold during the study (coded as present at baseline and absent after intervention). This was not considered in the statistical analyses.

None of the clinician or practice characteristics which included size of practice, location of practice, clinician number of years in practice, clinician decision making authority, clinician perceived importance of prevention, initial mean ACIC score, baseline estimates of performance, and actual performance at baseline, predicted whether a practice would implement one or more of the evidence-based approaches. The only significant predictor was group assignment $(P=$ $.05)$. Clinician and practice characteristics also failed to predict number of approaches imple- 
Table 2. Primary Outcome Measures (Adoption of Evidence-Based Strategies)

\begin{tabular}{|c|c|c|c|}
\hline Outcome & Intervention Group & Control Group & $P^{*}$ \\
\hline \multicolumn{4}{|c|}{ Improvements/opportunities } \\
\hline Total & $20 / 38$ & $4 / 23$ & .003 \\
\hline Adult & $13 / 26$ & $4 / 19$ & .05 \\
\hline Children & $7 / 12$ & $0 / 4$ & .042 \\
\hline \multicolumn{4}{|c|}{ Recall and reminders/opportunities } \\
\hline Total & $6 / 8$ & $1 / 4$ & .10 \\
\hline Adult & $5 / 7$ & $1 / 4$ & .14 \\
\hline Children & $1 / 1$ & $0 / 0$ & .16 \\
\hline \multicolumn{4}{|c|}{ Standing orders/opportunities } \\
\hline Total & $9 / 14$ & $1 / 8$ & .02 \\
\hline Adult & $6 / 8$ & $1 / 5$ & .05 \\
\hline Children & $3 / 6$ & $0 / 3$ & .13 \\
\hline \multicolumn{4}{|c|}{ Wellness visits/opportunities } \\
\hline Total & $5 / 16$ & $2 / 10$ & .53 \\
\hline Adult & $2 / 11$ & $2 / 10$ & .92 \\
\hline Children & $3 / 5$ & $0 / 0$ & .27 \\
\hline \multicolumn{4}{|c|}{ Clinicians improved/opportunities } \\
\hline Total & $9 / 12$ & $4 / 12$ & .06 \\
\hline Adult & $8 / 12$ & $4 / 12$ & .15 \\
\hline Children & $5 / 11$ & $0 / 7$ & .04 \\
\hline
\end{tabular}

*Binomial proportions test.

mented, which was predicted by group assignment $(P=.05)$ and the number of implementation opportunities $(P=.04)$. There were no meaningful correlations between level of readiness to improve or confidence in the practice's ability to improve and actual improvement.

Table 3 includes baseline and postintervention rates of delivery of selected preventive services. For all services except colorectal cancer screening, the intervention group improved more than the control group, although the differences were only statistically significant for mammography $(P=0.04)$.

Five facilitators were involved in the project, each working with one to 3 practices (Table 4).
They made weekly contacts with the practices, either in person ( $90 \%$ of the contacts) or by phone. The average number of visits made by the facilitators to each practice was 18 (range, 8-42) and the average total contact time with the clinicians was 446 minutes ( 7.4 hours; range, $80-$ 2640 minutes). There was no significant correlation between the number of facilitator visits or contact time and the number of processes implemented. There was also no evidence that some facilitators were more effective than others. One of the practices decided to add a prevention nurse. The facilitator spent 2640 minutes with that clinician in 42 visits.

Table 3. Changes in Rates of Delivery of Selected Preventive Services

\begin{tabular}{|c|c|c|c|c|c|c|}
\hline \multirow[b]{2}{*}{ Preventive Service } & \multicolumn{3}{|c|}{ Intervention Group (mean \% [SD]) } & \multicolumn{3}{|c|}{ Control Group (mean \% [SD]) } \\
\hline & Before & After & $P^{*}$ & Before & After & $P^{*}$ \\
\hline DTaP\#4 & $50(29)$ & $56(20)$ & .57 & $67(17)$ & $66(32)$ & .94 \\
\hline MMR & $56(30)$ & $63(23)$ & .57 & $74(15)$ & $75(19)$ & .73 \\
\hline НерВ\#3 & $54(32)$ & $67(16)$ & .24 & $69(16)$ & $72(33)$ & .72 \\
\hline Pneumovax & $15(20)$ & $25(23)$ & .11 & $40(30)$ & $41(32)$ & .86 \\
\hline Mammography & $33(16)$ & $60(18)$ & .001 & $54(17)$ & $61(28)$ & .26 \\
\hline CRC screen & $28(15)$ & $44(18)$ & .001 & $30(15)$ & $46(23)$ & .02 \\
\hline
\end{tabular}

${ }^{*}$ Paired $t$ tests.

MMR, measles/mumps/rubella; CRC, colorectal cancer. 
Table 4. Amount of Support and Measures of Improvement in Multi-Component Intervention Practices

\begin{tabular}{|c|c|c|c|c|c|c|c|}
\hline Practice & $\mathrm{PF}$ & $\begin{array}{c}\text { PEA } \\
\text { Visits (n) }\end{array}$ & $\begin{array}{l}\text { PEA Contact } \\
\text { Time (min) }\end{array}$ & $\begin{array}{l}\text { IT Visits } \\
\text { (n) }\end{array}$ & $\begin{array}{l}\text { Implementation/ } \\
\text { Opportunities (n) }\end{array}$ & $\begin{array}{c}\text { Processes } \\
\text { Implemented (n) }\end{array}$ & $\begin{array}{c}\text { Types of } \\
\text { Improvements }\end{array}$ \\
\hline 1 & A & 20 & 125 & 4 & 3 & 3 & $\begin{array}{l}\text { SOc, WVc, } \\
\text { WVa }\end{array}$ \\
\hline 2 & A & 25 & 385 & 5 & 3 & 2 & RRa, SOa \\
\hline 3 & A & 9 & 195 & 3 & 2 & 0 & \\
\hline 4 & B & 42 & 2640 & 3 & 5 & 4 & $\begin{array}{l}\text { RRa, SOc, } \\
\quad \text { SOa, WVc }\end{array}$ \\
\hline 5 & B & 19 & 310 & 1 & 4 & 0 & \\
\hline 6 & $\mathrm{C}$ & 14 & 470 & 1 & 3 & 2 & $\mathrm{RRa}, \mathrm{SOa}$ \\
\hline 7 & $\mathrm{D}$ & 10 & 80 & 1 & 1 & 0 & \\
\hline 8 & $\mathrm{D}$ & 21 & 370 & 1 & 4 & 3 & $\begin{array}{l}\text { SOc, SOa, } \\
\text { WVa }\end{array}$ \\
\hline 9 & $\mathrm{D} / \mathrm{E}$ & 12 & 110 & 1 & 1 & 1 & $\mathrm{SOa}$ \\
\hline 10 & $\mathrm{E}$ & 8 & 250 & 1 & 4 & 2 & $\mathrm{RRa}, \mathrm{SOa}$ \\
\hline 11 & $\mathrm{E}$ & 15 & 190 & 1 & 3 & 2 & $\mathrm{RRa}, \mathrm{WVc}$ \\
\hline 12 & $\mathrm{E}$ & 19 & 225 & 1 & 5 & 1 & $\mathrm{RRc}$ \\
\hline Medians & & 17 & 237 & 1 & 3 & 2 & \\
\hline
\end{tabular}

PF, practice facilitator (A-E represent 5 different facilitators); IT, information technology expert; Soc, standing orders for children; SOa, standing orders for adults; RRc, recall and reminders for children; RRa, recall and reminders for adults; WVc, wellness visits for children; WVa, wellness visits for adults.

Facilitator field notes documented that none of the practices held regular mandatory staff meetings before this project. Scheduled facilitator meetings were frequently changed or cancelled at the last minute because of patient care issues, clinician and staff illnesses, vacations, or scheduling errors. The idea of "Plan-Do-Study-Act" cycles was helpful, but the cycles rarely went as planned. Most of the practices had either recently implemented an electronic health record or were about to implement one. Two were in the middle of major moves or renovations of their offices.

The IT professional helped 4 of the intervention clinicians try to implement the PSRS software, 3 of whom did so successfully (Table 4). He provided advice to several practices regarding the choice of an electronic health record with respect to recall/ reminder functions. On average, he made 2 trips to each intervention group practice (range, 1-5). There were no significant associations between the number of IT support visits and the number of processes implemented.

\section{Discussion}

The multicomponent translational intervention was effective in these self-selected, motivated small primary care practices. Standing orders and recall and reminder systems, which were easier to implement than routine wellness visits, were implemented more often. As expected, implementation of the evidence-based processes seemed to result in increased delivery of all the preventive services that we measured, but the study was underpowered and too short in duration to show statistical significance for this secondary outcome measure.

This multicomponent implementation strategy has also been effective for improving the quality of care provided to diabetic patients, ${ }^{46}$ for increasing mammography rates, ${ }^{47}$ and for increasing rates of screening and interventions for unhealthy behaviors (unpublished). Other researchers have been successful using similar strategies. For example, Baskerville et $\mathrm{al}^{48}$ reported their successful introduction of effective preventive service delivery processes into a group of Canadian practices using a strategy that included audits with feedback, clinician education provided by opinion leaders, practice facilitators, within-practice consensus building, patient education materials, and the choice of a manual or computerized reminder system.

The cost of our intervention per practice was approximately $\$ 7,500$ for the 6-month implementation. Hogg et $\mathrm{al}^{49}$ analyzed the overall cost-effectiveness of their similar intervention, finding that, despite the high cost of facilitation, considering the 
increased rate of delivery of key preventive services the intervention was cost-effective.

Six months was barely enough time to effect these changes in most of our practices. This was partly because of the many other changes the practices were making on an ongoing basis. Even these practices, which chose to join a practice-based research network and then chose to be a part of a major quality improvement project, were unlikely to have implemented a majority of the components of the Chronic Care Model. They were extremely unlikely to have blocked out time to do quality improvement on a regular basis. We were unable to predict which practices would succeed using a variety of standard clinician and practice variables. This remains an important area for further study.

We did not specifically include measures of the practice's or clinician's priority for making the recommended changes or the practice's change process capability as specified in Solberg's Quality Improvement Model. ${ }^{50} \mathrm{We}$ did use the ACIC instrument to measure care process content and found no correlation with implementation. The lack of correlation of improvements with baseline practice characteristics might suggest that the multicomponent intervention can be effective across a range of practices and clinicians.

Our study has some limitations. The control practices had fewer opportunities to improve. Although the statistical analyses took that into account, it is still possible that this baseline difference could have unduly favored the intervention group. Blinding of the practices was impossible. The intervention clinicians knew that we were investing a great deal of time and effort into helping them implement the evidence-based approaches. This could have influenced their responses to the interview questions, leading them to overestimate the degree of implementation compared with the control clinicians. The trends seen in preventive service delivery rates are reassuring. Unfortunately, we were unable to conduct follow-up interviews to determine the extent to which the improvements were sustained and preventive services delivery rates continued to rise.

\section{Conclusions}

A multicomponent intervention that included performance feedback with benchmarking, academic detailing, practice facilitation, and IT support was more effective than performance feedback with benchmarking alone on the implementation of processes associated with increased delivery of preventive services in a group of primary care practices. The cost per practice was relatively high, but cost could possibly be reduced by integration within a continuous quality improvement infrastructure involving multiple practices.

\section{Note}

The Assessment of Chronic Illness Care (ACIC) survey instrument (version 3.5, modified by the authors for preventive services) mentioned in the article is available from the corresponding author by request.

\section{References}

1. Gyorkos T, Tannenbaum T, Abrahamowicz M, et al. Evaluation of the effectiveness of immunization delivery methods. Can J Public Health 1994; 85(Suppl 1):S14-S30.

2. Reviews of evidence regarding interventions to improve vaccination coverage in children, adolescents, and adults. Database of abstracts of review of effectiveness, vol. 1. York (UK): University of York; 2004.

3. McKibben LJ, Stange PV, Sneller VP, Strikas RA, Rodewald LE, Advisory Committee on Immunization Practices. Use of standing orders programs to increase adult vaccination rates. MMWR Recomm Rep 2000;49(RR-1):15-6.

4. Hunt DL, Haynes RB, Hanna SE, Smith K. Effects of computer-based clinical decision support systems on physician performance and patient outcomes-a systematic review. JAMA 1998;280:1339-46.

5. Shea S, DuMouchel W, Bahamonde L. A metaanalysis of 16 randomized controlled trials to evaluate computer-based clinical reminder systems for preventive care in the ambulatory setting. JAMIA 1996;3:399-409.

6. Mitchell E, Sullivan F. A descriptive feast but an evaluative famine: systematic review of published articles on primary care computing during 1980-97. BMJ 2001;322:279-82.

7. Yarnall K, Rimer B, Hynes D, et al. Computerized prompts for cancer screening in a community health center. J Am Board Fam Pract 1998;11:96-104.

8. Nease DE, Green LA. ClinfoTracker: a generalizable prompting tool for primary care. J Am Board Fam Pract 2003;16:115-23.

9. Alemi F, Alemagno SA, Goldhagen J, et al. Computer reminders improve on-time immunization rates. Med Care 1996;34(10 Suppl):OS45-51.

10. Stone EG, Morton SC, Hulscher ME, et al. Interventions that increase use of adult immunization and cancer screening services: a meta-analysis. Ann Int Med 2002;136:641-51. 
11. Nowalk M, Bardella I, Zimmerman R, Shen S. The physician's office: can it influence adult immunization rates? Am J Manag Care 2004;10:13-9.

12. Zimmerman R, Nowalk M, Bardella I, et al. Physician and practice factors related to influenza vaccination among the elderly. Am J Prev Med 2004;26: $1-10$.

13. Hulscher M, Wensing M, Grol R, van der Weijden $\mathrm{T}$, van Weel C. Interventions to improve the delivery of preventive services in primary care. Am J Public Health 1999;89:737-46.

14. Dickey L, Gemson D, Carney P. Office system interventions supporting primary care-based health behavior change counseling. Am J Prev Med 1999; 17(4):299-308.

15. Yarnall K, Pollak K, Ostbye T, Krause K, Michener J. Primary care: is there enough time for prevention? Am J Public Health 2003;93:635-41.

16. Yano EM, Fink A, Hirsch SH, Robbins AS, Rubenstein LV. Interventions improve primary care processes but not necessarily outcomes. Arch Intern Med 1995;155:1146-56.

17. Oxman AD, Thomson MA, Davis DA, Haynes RB. No magic bullets: a systematic review of 102 trials of interventions to improve professional practice. Can Med Assoc J 1995;153:1423-31.

18. Grol R, Wensing M. What drives change? Barriers to and incentives for achieving evidence-based practice. MJA 2004;180(Suppl):S57-S60.

19. Green LA, Seifert CM. Translation of research into practice: why we can't "just do it”? J Am Board Fam Pract 2005;18:541-5.

20. Lenfant C. Clinical research to clinical practice-lost in translation? N Engl J Med 2003;349:868-74.

21. Moulding NT, Silagy CA, Weller DP. A framework for effective management of change in clinical practice: dissemination and implementation of clinical practice guidelines. Qual Health Care 1999;8:177-83.

22. Kanouse DE, Jacoby I. When does information change practitioners' behavior? Int J Technol Assess Health Care 1988;4:27-33.

23. Jamtvedt G, Young JM, Kristofferson DT, O'Brien MA, Oxman AD. Audit and feedback: effects on professional practice and health care outcomes. Cochrane Database Syst Rev 2006;19(2):CD000259.

24. Kiefe CI, Allison JJ, Williams OD, Person SD, Weaver MT, Weissman NW. Improving quality improvement using achievable benchmarks for physician feedback: a randomized controlled trial. JAMA 2001;285:2871-9.

25. Goldstein MG, Niaura R, Willey C, Kazura A, Rakowski W, DePue J. An academic detailing intervention to disseminate physician-del smoking cessation counseling: smoking cessation outcomes of the Counseling Smokers Project. Prev Med 2003;36:185-96.

26. Ilett KF, Johnson S, Greenhill G, Mullen L, Brockis J, Golledge CL. Modification of general practitioner pre- scribing of antibiotics by therapeutics adviser (academic detailer). Br J Clin Pharmacol 2000;49:168-73.

27. Young JM, Ward JE. Randomised trial of intensive academic detailing to promote optimal recruitment of women to cervical screening by general practitioners. Aust N Z J Public Health 2003;27:273-81.

28. Brown JB, Shye D, McFarland BH, Nichols GA, Mullooly JP, Johnson R. Controlled trials of CQI and academic detailing to implement a practice guideline for depression. Jt Comm J Qual Improv 2000;26:39-54.

29. O'Brien T, Oxman AD, Davis DA, Haynes RB, Freemantle M. Educational outreach visits: effects on professional practice and outcomes. Cochrane Database Syst Rev 2000;(2):CD000409.

30. Mold JW, Gregory ME. Best practices research. Fam Med 2003;35:131-4.

31. Nagykaldi Z, Mold J, Aspy C. Practice facilitators: a review of the literature. Fam Med 2005;37:581-8.

32. Baskerville NB, Hogg W, Lemelin J. Process evaluation of a tailored multifaceted approach to changing family physician practice patterns improving preventive care. J Fam Pract 2001;50:W242-9.

33. Frijling BD, Lobo CM, Hulscher ME, et al. Multifaceted support to improve clinical decision making in diabetes care: a randomized controlled trial in general practice. Diabet Med 2002;19:836-42.

34. Dietrich AJ, O'Connor GT, Keller A, Carney PA, Levy D, Whaley FS. Cancer: improving early detection and prevention. A community practice randomized trial. BMJ 1992;304:687-91.

35. Goodwin MA, Zyzanski SJ, Zronek S, et al. A clinical trial of tailored office systems for preventive service delivery. The Study to Enhance Prevention by Understanding Practice (STEP-UP). Am J Prev Med 2001;21:20-8.

36. Modell M, Wonke B, Anionwu E, et al. A multidisciplinary approach for improving services in primary care: randomized controlled trial of screening for haemoglobin disorders. BMJ 1998;317:788-91.

37. Kinsinger LS, Harris R, Qaqish B, Sstrecher V, Kaluzny A. Using an office system intervention to increase breast cancer screening. J Gen Intern Med 1998;13:507-14.

38. Margolis PA, Lannon CM, Stuart JM, Fried BJ, Keyes-Elstein L, Moore DE Jr. Practice-based education to improve delivery systems for prevention in primary care: randomized trial. BMJ 2004;328:388.

39. Bryce FP, Neville RG, Crombie IK, Clark RA, McKenzie P. Controlled trial of an audit facilitator in diagnosis and treatment of childhood asthma in general practice. BMJ 1995;310:838-42.

40. Rogers E. The change agent. In: Rogers E (ed). Diffusion of innovations, fourth ed. New York (NY): Simon and Schuster, The Free Press; 1995:335-70.

41. Committee on Quality of Health Care in America. Crossing the quality chasm: a new health system for 
the 21st century. Washington DC: National Academy Press; 2001.

42. Nagykaldi Z, Fox C, Gallo S, et al. Improving collaboration among primary care practice-based research networks using access grid technology. J Am Board Fam Med 2007;20:188-95.

43. ACIC: Tools for improvement: assessment of chronic illness Care (ACIC). The assessment of chronic illness care (ACIC). Available from http:// www.improvingchroniccare.org/index.php?p=ACIC_ Survey\&s=35. MacColl Institute for Healthcare Innovation, Group Health Cooperative; 2002.

44. Bodenheimer T, Wagner EH, Grumbach K. Improving primary care for patients with chronic illness. JAMA 2002;288:1775-9.

45. Glasgow RE, Orleans CT, Wagner EH, et al. Does the Chronic Care Model serve also as a template for improving prevention? Milbank Q 2001;79:579-612.
46. Nagykaldi Z, Mold JW. Diabetes patient tracker, a personal digital assistant-based diabetes management system for primary care practices in Oklahoma. Diabetes Technol Ther 2003;5:997-1001.

47. Aspy CB, Enright M, Halstead L, Mold JM. Improving mammography screening using best practices and practice enhancement assistants: an OKPRN study. J Am Board Fam Med 2008;21:326-33.

48. Baskerville ND, Hogg W, Lemelin J. Process evaluation of a tailored multifaceted approach to changing family physician practice patterns improving preventive care. J Fam Pract 2001;50:W242-9.

49. Hogg W, Baskerville N, Lemelin J. Cost savings associated with improving appropriate and reducing inappropriate preventive care: cost-consequences analysis. BMC Health Serv Res 2005;5:20.

50. Solberg LI. Improving medical practice: a conceptual framework. Ann Fam Med 2007;5:2251-6. 